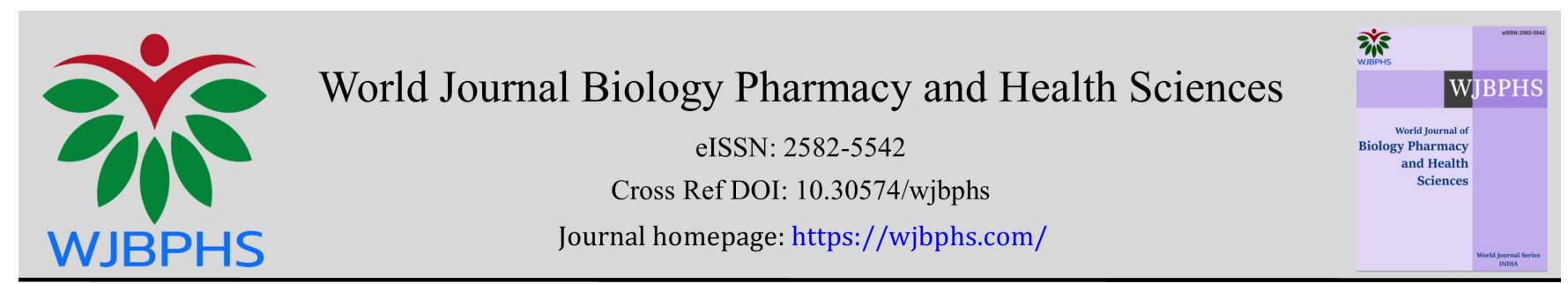

(RESEARCH ARTICLE)

\title{
Treatment of atherogenic dyslipidaemia in Primary Care in Spain
}

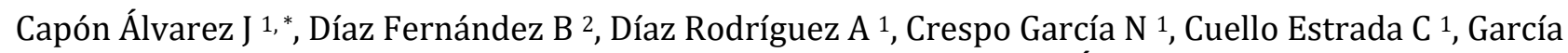 \\ Ferreiro T ${ }^{1}$, Rodríguez Pérez, EM ${ }^{1}$, Méndez Rodríguez E ${ }^{1}$, Fernández Álvarez, A ${ }^{3}$ and Seco Calvo JA ${ }^{4}$ \\ ${ }^{1}$ Medical Doctor, Primary Care Bembibre Center, León, Spain; University of Leon - UNILEON (Spain). \\ 2 Medical Doctor, University of Salamanca, Salamanca, Spain. \\ ${ }^{3}$ Nursing, Bierzo Hospital, Ponferrada (León), Spain. \\ 4 Profesor, University of León, IBIOMED, León, Spain.
}

World Journal of Biology Pharmacy and Health Sciences, 2021, 06(01), 026-038

Publication history: Received on 04 February 2021; revised on 11 April 2021; accepted on 14 April 2021

Article DOI: https://doi.org/10.30574/wjbphs.2021.6.1.0013

\begin{abstract}
Objective: Describe the treatment of the patient with atherogenic dyslipidaemia (AD) in routine Primary Care clinical practice.

Methodology: Observational, descriptive, cross-sectional study based on a structured questionnaire. The content of the questionnaire was based on a review of the literature and was validated by 3 AD experts. It included 23 questions and was addressed to primary care physicians. This sub study will analyze questions related to the treatment of AD.

Results: A total of 1,029 Primary Care physicians (67.06\% men) participated in the study. Most work in urban areas (55.9\%) and attended to a mean of 79.9 (SD: 89.85) patients with AD per month. Most (95.63\%) considered that the first step in treatment is lifestyle modification. For the AD approach associated with obesity in primary prevention, $74 \%$ of the participants advised lifestyle modifications and in turn evaluated the need for pharmacological treatment. In patients with moderate elevations of LDL-C and DA treated with statins, $90 \%$ of doctors associated fibrates. In these patients, 93\% agreed or fully agreed that fenofibrate is the most appropriate fibrate for their combination with statins. $19 \%$ consider the genfibrocil association. In patients in secondary prevention and AD, treated with statins with LDL-C in therapeutic objectives, the majority of participants (94.46\%) added a fibrate and $70 \%$ combined statins and fibrates from the start of treatment.
\end{abstract}

Conclusions: Although the level of inculcation of knowledge about the therapeutic management of AD is highly acceptable in some cases, there are parts that need to be modified, especially the poor association of statins with genfibrocil.

Keywords: Atherogenic dyslipidaemia; Primary care physicians; Treatment

\section{Introduction}

Atherogenic dyslipidaemia (AD) is a lipid and lipoprotein characterized by the association of low HDL-C, high TG and high proportion of small and dense LDL particles (atherogenic lipoprotein phenotype), with or without moderate cLDL$\mathrm{C}$ increase. These alterations are usually accompanied by an increase in non-HDL-C and as a result, an increase in apolipoprotein B (ApoB) [1-5].

\footnotetext{
* Corresponding author: Jessica Capón Álvarez

Primary Care Center Bembibre, León, Spain. University of Leon - UNILEON (Spain) Carbajal, 1. 24300 Bembibre (Spain). 
This type of dyslipidaemia is associated with increased cardiovascular risk and contributes significantly to increasing the residual vascular risk of lipid origin. It is present in Metabolic Syndrome, obesity, type 2 diabetes, established CVD, Chronic Renal Insufficiency and combined family dyslipidaemia [1,3]. As all of these diseases are increasing in prevalence, the prevalence of $\mathrm{AD}$ can be expected to increase in the future in parallel.

$\mathrm{AD}$ is very common in the Spanish population. The prevalence of $\mathrm{AD}$ is increased from $3 \%$ in the general population (ENRICA study) [6], to 6\% in the working population (ICARIA study) [7], to 10\% in primary care (ENRICA study) [6], to $14.3 \%$ in primary care (16.4\% in men $14.8 \%$ in women), (SIMETATAP-AD study) [8], to $14,8 \%$ primary care consultations (IBERICAN study) [9], to 18\% in Lipid Units (EDICONDIS-ULISEA study) [10]. This study revealed that only 1 in 6 patients with AD achieved the treatment goals for HDL-C and TG and that approximately $20 \%$ of patients who achieved these goals received pharmacological treatment.

The prevalence of AD in Europe is 20\% and 55\% remain untreated (EURIKA study) [11]. The EUROASPIRE V study showed that only $32 \%$ of patients treated with lipid-lowering drugs were adequately controlled [12].

The latest guidelines and Consensus for the control of dyslipidaemia recommend cLDL as a control objective, but in the presence of elevated TG and/or low C-HDL, recommend as control objectives non-HDL cholesterol and Apo B [1, 4, 1315].

Initial AD treatment recommendations include lifestyle modifications, including diet, exercise, no alcohol intake, no smoking, and weight control as a fundamental treatment strategy. The pharmacological treatment of choice is statins in monotherapy or in combination with ezetimibe to control LDL-C. In the presence of AD, and once cLDL is controlled, fenofibrate will be added to statin treatment to achieve the control objectives of non-HDL cholesterol [1, 4, 13-15].

Knowing the treatment of the patient in the usual clinical practice by the primary care physician can provide fundamental information to improve the early treatment and the degree of control of patients in the Spanish healthcare system. The aim of this study was to describe the treatment of the patient with AD in routine Primary Care clinical practice.

\section{Material and methods}

\subsection{Design and study population}

An observational, descriptive, cross-sectional study was conducted by means of an ad hoc online questionnaire addressed to Primary Care physicians. The fieldwork took place between 21 April and 29 July, 2016. At the time of their participation, the physicians had exerted their profession for at least 5 years and were working in the Spanish health system. The participants answered the questionnaire based on their routine clinical practice and did not receive a previous specific course related to AD.

The electronic questionnaire was available on a web portal that could be accessed through an individual and nontransferable password provided by CRO Outcomes'10, obtained by the user at the time of registration. The results of CRO Outcomes'10 were monitored during the study. All data entered in the database were verified when necessary.

The selection of the sample was made by cluster sampling, in which the primary units were the Autonomous Communities, the secondary units the health areas and the tertiary units, the primary care physicians. Their use as inclusion criteria, voluntary participation, sign informed consent, have exercised their profession for at least 5 years, be working in the National Health System (SNS), have not received previous AD related training and respond to the electronic questionnaire based on their usual clinical practice. Doctors with less than 5 years of experience, those who did not work in the NHS and those who had received previous AD training were excluded from the study.

The minimum sample size (1,009 Primary Care physicians) was estimated based on the assumption of maximum variability, the number of Primary Care physicians exerting their profession in the Spanish public health system in 2015 $(37,648)[16]$, a $99 \%$ confidence level and a precision error of $4 \%$.

\subsection{Questionnaire design}

A specific electronic structured questionnaire was developed for data collection. The content of the questionnaire was based on information collected by means of a review of the literature on the management of and approach to AD in routine clinical practice. The questionnaire was validated by three experts in the management of AD. 
The questionnaire consisted of 23 items across 4 sections: 1) residual cardiovascular risk (3 items); 2) general aspects of $\mathrm{AD}$ (4 items); 3) diagnosis of $\mathrm{AD}$ (5 items); and 4) treatment of AD (11 items) (Supplementary Material). The questions were formulated with closed polytomous or categorized responses. Seven questions required responses via a Likert scale with values of 1 to 4 (not useful-very useful) or 1 to 5 (completely disagree-completely agree). The sociodemographic variables of the participants (age, gender, years of profession, personal history of AD, province in which they practiced their profession, and the area where their health centre was located [rural $(<5,000$ inhabitants $)$, semiurban $(5,000$ to 19,999 inhabitants), or urban $(\geq 20,000$ inhabitants)] were also collected.

\subsection{Variables studied}

This article analyzes the sociodemographic variables of the participants (age, sex, years of profession, personal history of $\mathrm{AD}$ province in which they practiced their profession and the area where their health center was located, background of DA, Lifestyle modifications; benefits of treatment; management of AD treatment; use of statins, ezetimibe, fibrates, omega 3, nicotinic acid, ion exchange resins; treatment of low C-HDL, triglycerides as a cardiovascular risk factor; use of the most appropriate fibrate to combine with statins; treatment of AD in obese patients with metabolic syndrome and acute coronary syndrome.

\subsection{Statistical analysis}

The statistical analysis was performed using the STATA version 14 statistical package. Frequency tables were used to detect anomalies in the introduction of each of the study variables and contingency tables to detect repeated or inconsistent cases. In all statistical tests, a value of $\mathrm{p}<0.05$ was considered significant. Relative and absolute frequencies were calculated for qualitative variables. For quantitative variables, means, standard deviations and the distribution of percentiles were estimated. Relative and absolute frequencies were calculated for qualitative variables. The Chi-square test was used to compare categorical variables between groups. Kruskal-Wallis were performed to compare continuous variables between subgroups. With regard to the questions whose responses were scored by means of a Likert scale, relative and absolute frequencies and $95 \%$ confidence intervals were calculated.

\subsection{Ethical considerations}

The study was approved by the Clinical Research Ethics Committee of Hospital Universitario Puerta de Hierro, Majadahonda, Madrid. All participants received information relevant to the study and gave their consent to participate in it.

\section{Results}

\subsection{Socio-demographic characteristics of the sample}

Table 1 Socio-demographic characteristics of the sample

\begin{tabular}{|l|l|}
\hline Characteristics & N $=\mathbf{1 . 0 2 9}(\%)$ \\
\hline Age [mean (SD)], years & $53.47(7.78)$ \\
\hline Men [n (\%)] & $690(67.06)$ \\
\hline Area where the healthcare is located [n (\%)] & $182(17.69)$ \\
\hline Rural (<5.000 inhabitants) & $271(26.34)$ \\
\hline Semi-urban (5.000-19.999 inhabitants) & $576(55.98)$ \\
\hline Urban ( $\geq 20.000$ inhabitants) & $26.54(8.29)$ \\
\hline Time practicing the profession [mean (SD)], years & $147(85.71)$ \\
\hline Personal history of AD [n (\%)] & $882(14.29)$ \\
\hline Yes & $76.90(89.85)$ \\
\hline No & \\
\hline Approximate number of patients with AD that visits per month [mean (SD)], years & \\
\hline
\end{tabular}


A total of 1,029 Primary Care physicians (67.06\% men) participated in the study. The average age of the participants was 53.48 (SD: 7.78) years and the average number years of professional activity was 26.54 (SD: 8.29). Physicians from all Spanish autonomous regions participated, with Andalusia, the Valencian Community and the Community of Madrid being the most represented $(15.5 \%, 13.9 \%$ and $10.1 \%$, respectively), the least represented were the Balearic Islands, La Rioja, Ceuta and Melilla (1.26\%, 1.17\% and 0.29 respectively). The majority of participants exercised their profession in centers located in urban areas (55.9\%), followed by semi-urban areas (26.4\%) and rural areas (17.7\%). The participants attended to a mean of 79.9 (SD: 89.85) patients with AD per month. The socio-demographic characteristics of participants are shown in Table 2.

Table 2 Questionnaire for Professionals

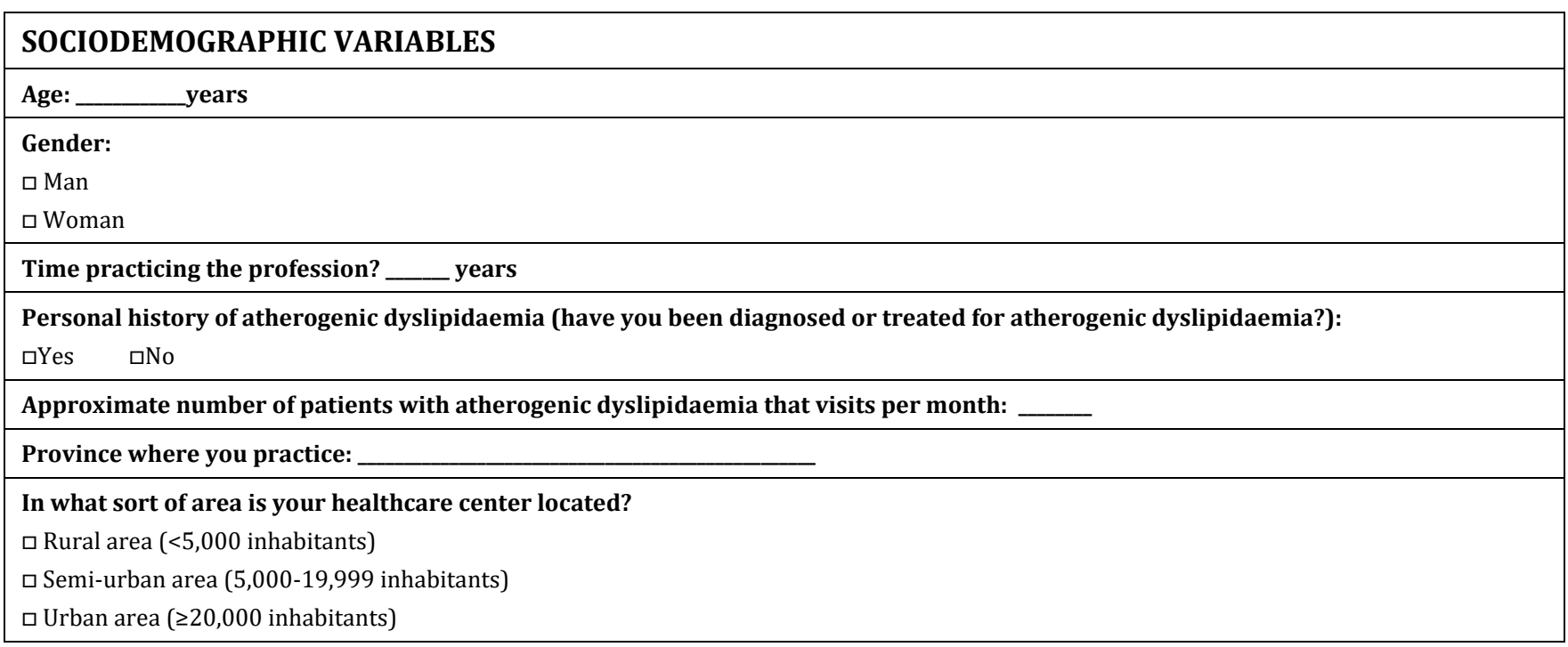

\section{RESIDUAL CARDIOVASCULAR RISK}

1.1 Do you evaluate residual cardiovascular risk in your routine clinical practice?

$\square$ Yes, but only in patients in secondary prevention.

$\square$ I'm not sure what residual cardiovascular risk is.

$\square$ Yes, whenever I remember.

$\square$ No, because residual risk is a theoretical concept with no clinical impact.

1.2 What do you think lipid-related residual cardiovascular risk refers to?

$\square$ The risk that persists after controlling the patient's weight.

$\square$ The risk that persists after treating the patient with statins and achieving LDL-C objectives.

$\square$ The risk that persists after controlling all modifiable risk factors.

$\square$ The risk that persists after quitting smoking as a major risk factor.

1.3 To what do you attribute lipid-related residual cardiovascular risk?

$\square$ Age

$\square$ Arterial hypertension

$\square$ Obesity

$\square$ Atherogenic dyslipidaemia

\section{ATHEROGENIC DYSLIPIDAEMIA}

2.1 In your opinion, what are the characteristics of atherogenic dyslipidaemia?

$\square$ Elevated LDL-C.

$\square$ Normal or moderately elevated LDL-C levels and a phenotype of small, dense LDL-C particles.

$\square$ Low HDL-C and elevated triglycerides (TG).

$\square$ Low HDL-C, elevated TG, and elevated small, dense LDL-C particles.

2.2 Please indicate any phenotype you think is associated with atherogenic dyslipidaemia:

$\square$ Early coronary disease.

$\square$ Metabolic syndrome. 
$\square$ Type 2 diabetes.

$\square$ All of the above.

2.3 Please tick the statement that you think is the most accurate:

$\square \mathrm{AD}$ is not associated with a high or very high cardiovascular risk.

$\square$ AD is of no particular importance in type 2 diabetes, either with regard to macrovascular or microvascular complications.

$\square \mathrm{AD}$ is a determinant factor for cardiovascular risk, even if LDL-C levels are correct.

$\square$ AD does not occur in obese patients.

2.4 What prompts you to specifically assess $\mathrm{AD}$ in your clinical practice?

$\square$ Because cardiovascular risk is increased.

$\square$ Because cardiovascular risk is increased by concomitant obesity.

$\square$ Because treatment with fibrates must be given.

$\square$ Because if it occurs along with diabetes, it should always be treated with insulin.

\section{ATHEROGENIC DYSLIPIDEMIA DIAGNOSIS}

3.1 What parts of the lipid profile do you consider essential for evaluating a patient with atherogenic dyslipidemia?

$\square$ Total cholesterol.

$\square$ Total cholesterol and HDL-C.

$\square$ Total cholesterol, TG, and HDL-C.

$\square$ Total cholesterol, TG, HDL-C, LDL-C and non-HDL cholesterol.

3.2 In a 58-year-old man with a diagnosis of metabolic syndrome, what would be the target for lipid control?

$\square$ Triglycerides.

$\square$ HDL-C.

$\square$ LDL-C.

$\square$ Non-HDL cholesterol.

3.3 In your clinical practice, can you request fractionated total cholesterol to assess HDL-C and LDL-C?

$\square$ No.

$\square$ Yes, but I am guided by total cholesterol only.

$\square$ Yes, but by referring the patient.

$\square$ Yes, routinely and without restrictions.

3.4 How often do you use the following lipoprotein ratios? Considering 1: never; 2: almost never; 3: sometimes; 4: often; 5: very often.

\begin{tabular}{|l|l|l|l|l|l|}
\hline & Never & Almost never & Sometimes & Often & Very often \\
\hline TC/HDL-C ratio & & & & & \\
\hline LDL-C/HDL-C ratio & & & & & \\
\hline ApoB/ApoA1 ratio & & & & & \\
\hline Non-HDL-C/HDL-C ratio & & & & & \\
\hline TG/HDL-C ratio & & & & & \\
\hline LDL-C/ApoB ratio & & & & & \\
\hline
\end{tabular}

3.5 Please indicate how useful each of the atherogenic indexes is in clinical practice, even if you do not use them (Considering 1: not useful and 5: very useful)

\begin{tabular}{|l|l|l|l|l|}
\hline & Not useful & Of little use & Useful & Very useful \\
\hline TC/HDL-C ratio & & & & \\
\hline LDL-C/HDL-C ratio & & & & \\
\hline ApoB/ApoA1 ratio & & & & \\
\hline Non-HDL-C/HDL-C ratio & & & & \\
\hline TG/HDL-C ratio & & & & \\
\hline LDL-C/ApoB ratio & & & & \\
\hline
\end{tabular}




\begin{tabular}{|c|c|c|c|c|c|}
\hline \multicolumn{6}{|c|}{ ATHEROGENIC DYSLIPIDEMIA TREATMENT } \\
\hline \multicolumn{6}{|c|}{$\begin{array}{l}\text { 4.1 What do you think should be the first step in the treatment of atherogenic dyslipidaemia? } \\
\square \text { A diet adapted to achieve an appropriate BMI. } \\
\square \text { In addition to diet, smoking cessation, if applicable. } \\
\square \text { The above, plus regular physical exercise. } \\
\square \text { Diet, regular physical exercise, quitting smoking, and pharmacological treatment, if necessary. }\end{array}$} \\
\hline \multicolumn{6}{|c|}{$\begin{array}{l}\text { 4.2 How would you approach a patient with atherogenic dyslipidaemia associated with obesity? } \\
\square \text { Refer the patient to the nurse. } \\
\square \text { Refer the patient to the endocrinologist. } \\
\square \text { Treat the patient in conjunction with the nursing staff. } \\
\square \text { I emphasize the importance of lifestyle changes and I evaluate the use of pharmacological treatment. }\end{array}$} \\
\hline \multicolumn{6}{|c|}{ 4.3 Please indicate how far you agree with each of the following statements about treatment with statins. } \\
\hline & $\begin{array}{l}\text { Completely } \\
\text { disagree }\end{array}$ & $\begin{array}{l}\text { Partially } \\
\text { disagree }\end{array}$ & Indifferent & Partially agree & $\begin{array}{l}\text { Completely } \\
\text { agree }\end{array}$ \\
\hline \multicolumn{6}{|l|}{$\begin{array}{l}\text { Statins eliminate all residual cardiovascular } \\
\text { risk if target LDL-C levels are achieved. }\end{array}$} \\
\hline \multicolumn{6}{|l|}{$\begin{array}{l}\text { Pravastatin has an active hepatic } \\
\text { metabolism and should not be used in poly- } \\
\text { treated patients" }\end{array}$} \\
\hline \multicolumn{6}{|l|}{$\begin{array}{l}\text { The residual risk associated with high } \\
\text { triglycerides and/or low HDL-C is not } \\
\text { eliminated with statins alone. }\end{array}$} \\
\hline $\begin{array}{l}\text { If correctly undertaken, diet and quitting } \\
\text { smoking are generally sufficient to } \\
\text { eliminate the residual risk. }\end{array}$ & & & & & \\
\hline
\end{tabular}

4.4 How would you manage a patient with slightly elevated LDL-C, low HDL-C, and TG over $150 \mathrm{mg} / \mathrm{dl}$, who cannot achieve lipid control with a statin?

\begin{tabular}{|l|l|l|l|l|l|}
\hline & $\begin{array}{c}\text { Completely } \\
\text { disagree }\end{array}$ & Partially disagree & Indifferent & Partially agree & $\begin{array}{c}\text { Completely } \\
\text { agree }\end{array}$ \\
\hline I would double the dose of statins & & & & & \\
\hline I would add ezetimibe & & & & & \\
\hline I would add nicotinic acid & & & & & \\
\hline I would add a fibrate & & & & & \\
\hline I would add exchange resins & & & & \\
\hline
\end{tabular}

\subsection{What treatment do you think is the most appropriate for managing low HDL-C?}

\begin{tabular}{|l|l|l|l|l|}
\hline & Not useful & Of little use & Useful \\
\hline Fibrates & & & \\
\hline Statins & & & \\
\hline Omega-3 & & & & \\
\hline Nicotinic acid & & & \\
\hline
\end{tabular}

4.6 With regard to TG, please indicate how much you agree with the following statements:

\begin{tabular}{|l|c|c|c|c|c|}
\hline & $\begin{array}{c}\text { Completely } \\
\text { disagree }\end{array}$ & $\begin{array}{c}\text { Partially } \\
\text { disagree }\end{array}$ & Indifferent & Partially agree & $\begin{array}{c}\text { Completely } \\
\text { agree }\end{array}$ \\
\hline $\begin{array}{l}\text { They are not a cardiovascular risk "per } \\
\text { se" }\end{array}$ & & & & & \\
\hline
\end{tabular}




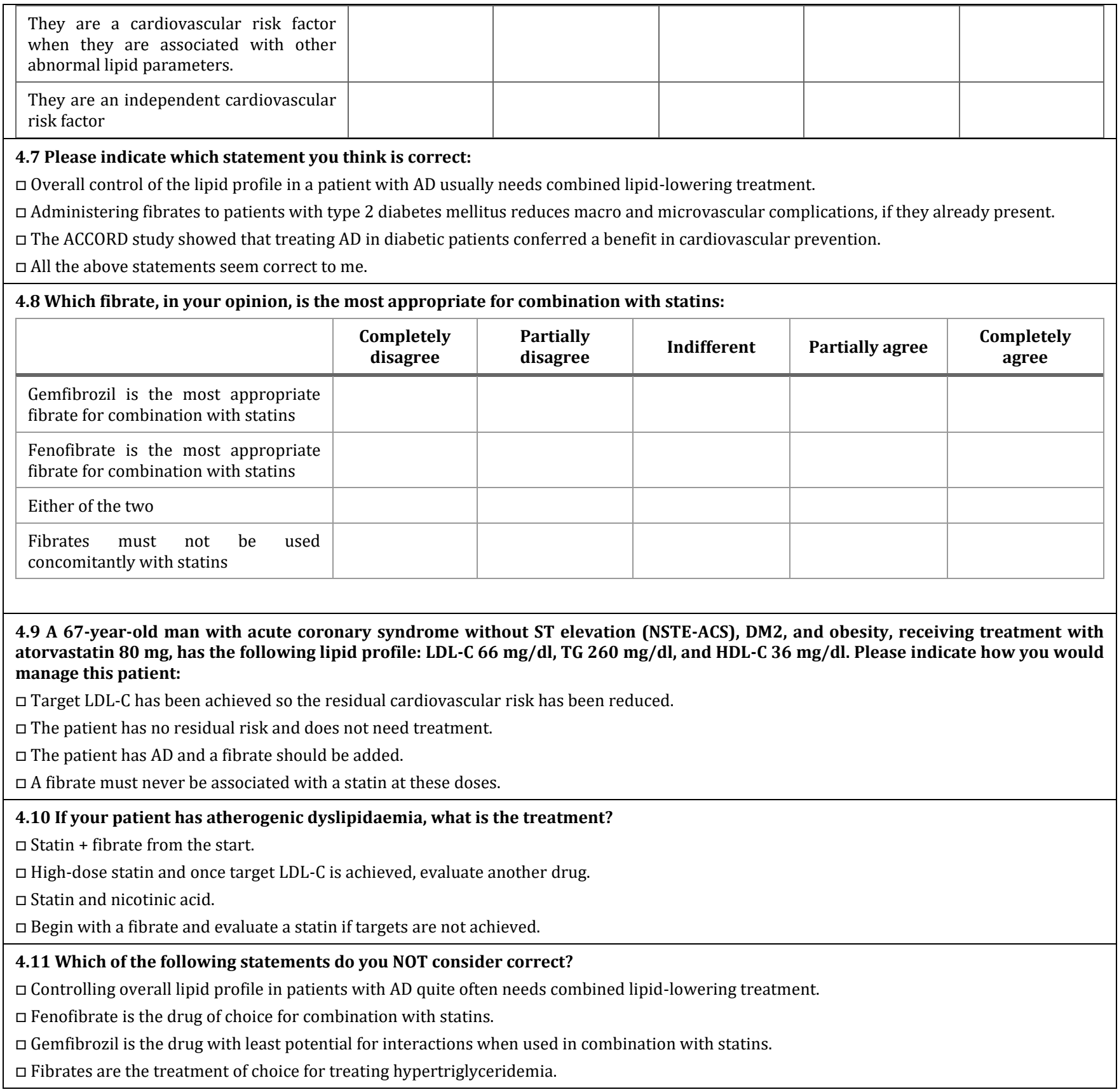

\subsection{Treatment of Atherogenic Dyslipidaemia}

The questionnaire included 11 questions related to the treatment of $\mathrm{AD}$, of which 4 were answered by means of a Likert scale.

First, the participants responded to two questions related to the initial treatment approach to AD. Most doctors $(95.63 \%)$ considered that the first step in treatment is lifestyle modifications (diet, regular physical exercise, smoking cessation) and, pharmacological treatment when necessary.

For the $\mathrm{AD}$ approach associated with obesity in primary prevention, $74 \%$ of the participants advised lifestyle modifications and in turn evaluated the need for pharmacological treatment, although $23 \%$ shared the treatment with nursing (Table 3). 
Table 3 Initial treatment of AD

\begin{tabular}{|l|l|l|}
\hline $\begin{array}{l}\text { What do you think should be the first step in the treatment of atherogenic } \\
\text { dyslipidaemia? }\end{array}$ & n & Percentage \\
\hline A diet adapted to achieve an appropriate BMI & 6 & $0.58 \%$ \\
\hline In addition to diet, smoking cessation, if applicable & 4 & $0.39 \%$ \\
\hline The above, plus regular physical exercise & 35 & $3.40 \%$ \\
\hline $\begin{array}{l}\text { Diet, regular physical exercise, quitting smoking, and pharmacological treatment, if } \\
\text { necessary }\end{array}$ & 984 & $95.63 \%$ \\
\hline Total & 1029 & $100.00 \%$ \\
\hline $\begin{array}{l}\text { How would you approach a patient with atherogenic dyslipidaemia associated with } \\
\text { obesity? }\end{array}$ & $\mathbf{n}$ & Percentage \\
\hline Refer the patient to the nurse & 4 & $0.39 \%$ \\
\hline Refer the patient to the endocrinologist & 27 & $2.62 \%$ \\
\hline Treat the patient in conjunction with the nursing staff & 237 & $23.03 \%$ \\
\hline $\begin{array}{l}\text { I emphasize the importance of lifestyle changes and I evaluate the use of pharmacological } \\
\text { treatment. }\end{array}$ & 761 & $73.96 \%$ \\
\hline Total & 1029 & $100.00 \%$ \\
\hline
\end{tabular}

As for the benefits of statin AD treatment, the participants indicated their degree of agreement or disagreement with 4 statements posed. The majority (91.54\%) indicated that they completely or partially agreed that "the residual risk associated with high TGs and/or low HDL-C is not eliminated with statins alone". Almost half of the participants (47.81\%) indicated that they completely or partially agreed with the statement "statins eliminate all residual cardiovascular risk if target LDL-C levels are achieved". $30.41 \%$ of participants completely or partially disagreed that "if correctly undertaken, diet and quitting smoking are generally sufficient to eliminate the residual risk". Finally, $18.86 \%$ of participants completely or partially disagreed that "pravastatin has an active hepatic metabolism and should not be used in poly-treated patients" (Table 4).

Table 4 Benefits of statin AD treatment

\begin{tabular}{|c|c|c|c|c|c|c|}
\hline \multirow[t]{2}{*}{ Statements } & $\begin{array}{l}\text { ou agree with } \\
\begin{array}{l}\text { Completely } \\
\text { disagree }\end{array} \\
\end{array}$ & $\begin{array}{l}\text { h of the follov } \\
\text { Partially } \\
\text { disagree }\end{array}$ & \begin{tabular}{|l|} 
ng statement \\
Indifferent
\end{tabular} & $\begin{array}{l}\text { Partially } \\
\text { agree }\end{array}$ & $\begin{array}{l}\text { Completely } \\
\text { agree }\end{array}$ & \\
\hline & n; \% & n; \% & n; \% & n; \% & n; \% & Total (n) \\
\hline $\begin{array}{l}\text { Statins eliminate all residual } \\
\text { cardiovascular risk if target LDL-C } \\
\text { levels are achieved }\end{array}$ & $252 ; 24.49 \%$ & $246 ; 23.91 \%$ & $39 ; 3.79 \%$ & $411 ; 39.94 \%$ & $81 ; 7.87 \%$ & 1029 \\
\hline $\begin{array}{l}\text { Pravastatin has an active hepatic } \\
\text { metabolism and should not be used } \\
\text { in poly-treated patients" }\end{array}$ & $437 ; 42.47 \%$ & $306 ; 29.74 \%$ & $92 ; 8.94 \%$ & $150 ; 14.58 \%$ & $44 ; 4.28 \%$ & 1029 \\
\hline $\begin{array}{l}\text { The residual risk associated with } \\
\text { high TGs and/or low HDL-C is not } \\
\text { eliminated with statins alone }\end{array}$ & $25 ; 2.43 \%$ & $38 ; 3.69 \%$ & $24 ; 2.33 \%$ & $287 ; 27.89 \%$ & $655 ; 63.65 \%$ & 1029 \\
\hline $\begin{array}{l}\text { If correctly undertaken, diet and } \\
\text { quitting smoking are generally } \\
\text { sufficient to eliminate the residual } \\
\text { risk }\end{array}$ & $254 ; 24.68 \%$ & $402 ; 39.07 \%$ & $60 ; 5.83 \%$ & $286 ; 27.79 \%$ & $27 ; 2.62 \%$ & 1029 \\
\hline
\end{tabular}

For the treatment of patients with moderately elevated LDL-C and AD levels that do not achieve lipid control with statins, primary care physicians reported using the 5-point Likert scale (1: completely disagree; 2 : partially disagree; 3 : indifferent; 4: partially agreed; 5: completely agreed) whether or not they agreed with 4 statements raised. The vast majority (90\%) agreed to add a fibrate, while $51 \%$ would associate ezetimibe and $30 \%$ would double the dose of statin (Figure1) 


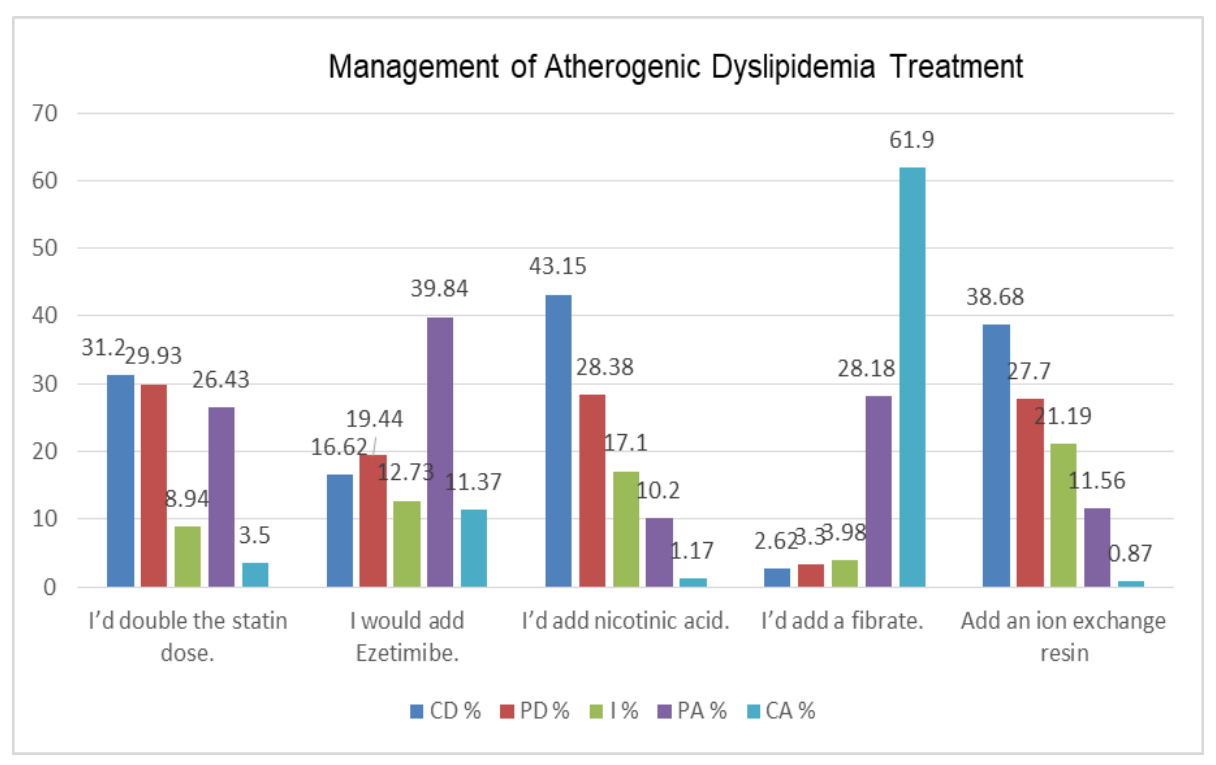

Figure 1 Management of Atherogenic Dyslipidaemia Treatment in patients treated with statins and lightly elevated LDL-C

Regarding the most appropriate treatment to treat low HDL-C, the participating physicians indicated the usefulness of 4 proposed treatments (fibrates, statins, omega-3 or nicotinic acid). More than half of participants (67.74\%) reported that fibrates were useful or very useful; $65.21 \%$ considered omega-3 to be useful or very useful; $64.53 \%$ considered that statins were useful or very useful; and finally, $29.45 \%$ replied that nicotinic acid was useful or very useful.

When asked about the degree of agreement or disagreement regarding triglycerides as a cardiovascular risk factor (CVRF), through a Likert scale, 82\% agreed or completely agreed that triglycerides are an independent CVRF; 69\% agreed that they are a CVRF when associated with alterations of other altered lipid parameters. Finally, $21 \%$ agreed that triglycerides are not a CVRF "per se".

In $\mathrm{AD}$ patients treated with statins, 93\% agreed or fully agreed that fenofibrate is the most appropriate fibrate for their combination with statins. Surprisingly, $19 \%$ considered genfibrocil more appropriate and $17 \%$ of both fibrates versus $7 \%$ of primary care physicians agreed that fibrates should not be combined with statins (Table 5).

Table 5 Fibrate more suitable for combiner with statins

\begin{tabular}{|c|c|c|c|c|c|c|}
\hline \multicolumn{7}{|c|}{ Which fibrate, in your opinion, is the most appropriate for combination with statins? } \\
\hline \multirow{2}{*}{ Options } & $\begin{array}{l}\text { Completely } \\
\text { disagree }\end{array}$ & $\begin{array}{l}\text { Partially } \\
\text { disagree }\end{array}$ & $\begin{array}{l}\text { Indiffer } \\
\text { ent }\end{array}$ & $\begin{array}{l}\text { Partially } \\
\text { agree }\end{array}$ & $\begin{array}{l}\text { Completely } \\
\text { agree }\end{array}$ & \\
\hline & & n; \% & n; \% & n; \% & n; \% & $\begin{array}{l}\text { Total } \\
\text { (n) }\end{array}$ \\
\hline Gemfibrozil & $\begin{array}{l}455 ; \\
44.22 \%\end{array}$ & $\begin{array}{l}239 ; \\
23.23 \% \\
\end{array}$ & $\begin{array}{l}138 ; \\
13.41 \% \\
\end{array}$ & $\begin{array}{l}167 ; \\
16.23 \% \\
\end{array}$ & $\begin{array}{l}30 \\
2.92 \% \\
\end{array}$ & 1029 \\
\hline Fenofibrate & \begin{tabular}{|l|}
$18 ;$ \\
$1.75 \%$ \\
\end{tabular} & \begin{tabular}{|l|}
$18 ;$ \\
$1.75 \%$ \\
\end{tabular} & \begin{tabular}{|l|}
30 \\
$2.92 \%$ \\
\end{tabular} & $\begin{array}{l}193 ; \\
18.76 \% \\
\end{array}$ & \begin{tabular}{|l|}
$770 ;$ \\
$74.83 \%$ \\
\end{tabular} & 1029 \\
\hline Either of the two & $\begin{array}{l}444 ; \\
43.15 \% \\
\end{array}$ & $\begin{array}{l}269 ; \\
26.14 \% \\
\end{array}$ & $\begin{array}{l}143 ; \\
13.90 \% \\
\end{array}$ & $\begin{array}{l}130 ; \\
12.63 \% \\
\end{array}$ & \begin{tabular}{|l|}
$43 ;$ \\
$4.18 \%$ \\
\end{tabular} & 1029 \\
\hline $\begin{array}{l}\text { Fibrates must not be used } \\
\text { concomitantly with statins }\end{array}$ & $\begin{array}{l}743 ; \\
72.21 \%\end{array}$ & $\begin{array}{l}180 ; \\
17.49 \%\end{array}$ & $\begin{array}{l}28 ; \\
2.72 \%\end{array}$ & $56 ; 5.44 \%$ & $\begin{array}{l}22 ; \\
2.14 \%\end{array}$ & 1029 \\
\hline
\end{tabular}

When the participants were asked the participants were asked to indicate which of the following questions was not correct: "controlling overall lipid profile in patients with AD quite often needs combined lipid-lowering treatment"; "fenofibrate is the drug of choice for combination with statins"; "gemfibrozil is the drug with least potential for interactions when used in combination with statins"; "fibrates are the treatment of choice for treating 
hypertriglyceridemia". Almost all the physicians (80.95\%) indicated that the statement concerning gemfibrozil was not correct.

Finally, in patients in secondary prevention, with acute coronary syndrome in treatment with statins with LDL-C in therapeutic objectives, presenting AD most (94.46\%) consider that a fibrate should be added and $70 \%$ considered that a combination of statins and fibrates should be prescribed from the beginning of treatment. A smaller proportion (19.14\%) considered that a patient with AD should be treated with a high-dose statin and, once target LDL-C is achieved, adding another drug should be evaluated. Furthermore, $10.79 \%$ considered that a fibrate must be administered to begin with and evaluate a statin if treatment targets are not achieved. Finally, only $0.10 \%$ of participants indicated that a statin and nicotinic acid should be administered (Table 6)

Table 6 Treatment of AD in secondary prevention

\begin{tabular}{|l|l|l|}
\hline $\begin{array}{l}\text { A 67-year-old man with acute coronary syndrome without ST elevation } \\
\text { (NSTEACS), DM2 and obesity, receiving treatment with atorvastatin 80 mg, has the } \\
\text { following lipid profile: cLDL 66 mg / dl, TG 260 mg / dl, and cHDL 36 mg / dl. } \\
\text { Indicate how you would handle this patient: }\end{array}$ & $\mathrm{n}$ & $\%$ \\
\hline $\begin{array}{l}\text { The cLDL objective has been achieved, thus the residual cardiovascular risk has } \\
\text { been reduced. }\end{array}$ & 19 & $1.85 \%$ \\
\hline The patient has no residual risk and needs no treatment. & 5 & $0.49 \%$ \\
\hline Patients have AD and should add a fibrate. & 972 & $94.46 \%$ \\
\hline A fibrate should never be associated with a statin in these doses. & 33 & $3.21 \%$ \\
\hline Total & 1,029 & $100.00 \%$ \\
\hline If your patient has AD, what is the treatment? & $\mathrm{n}$ & $\%$ \\
\hline Statin and fibrate from the beginning & 720 & $69.97 \%$ \\
\hline $\begin{array}{l}\text { Give statins in high doses and once the cLDL target is reached, another drug is } \\
\text { evaluated. }\end{array}$ & 197 & $19.14 \%$ \\
\hline Start with a fibrate and value a statin if goals are not achieved. & 111 & $10.79 \%$ \\
\hline Statin and nicotinic acid & 1 & $0.10 \%$ \\
\hline Total & 1029 & $100.00 \%$ \\
\hline
\end{tabular}

\subsection{Analysis of subgroups associated with the diagnosis of AD}

Subgroup analyses were performed to evaluate whether the responses related to the treatment of AD are associated with the primary variables (sociodemographic, personal history of $\mathrm{AD}$, years of professional practice, location and autonomous community of physicians). No relationship could be established between variables and responses ( $p>0.05$ ). We evaluated by age of doctors, $p=0.607$, by sex, $p=724$, years of practice of the profession, $p=0.457$, location of the health center, $\mathrm{p}=0.475$ and Autonomous Community, $\mathrm{p}=0486$.

\section{Discussion}

The results of our study show that $96 \%$ of primary care physicians considered lifestyle modifications as the first step in treating $\mathrm{AD}, 91 \%$ knew that the residual risk of lipid origin is not eliminated in patients treated with statins, $90 \%$ associated a fibrate to statins in the presence of AD. In this sense, 75\% considered fenofibrate as the most suitable fibrate to combine with statins, but unacceptably, $19 \%$ considered genfibrocil when it is contraindicated by toxicity.

The study has focused on Primary Care physicians, since they represent the first line of healthcare and are therefore key players in the early detection of the disease. The participants involved physicians practicing in rural, semi-urban and urban areas from all the Spanish autonomous communities. It should be noted that the participants' professional experience exceeded an average of 25 years (SD: 8.29), and so they are presumably familiar with the management of these patients.

As a comparative reference for the participants, the clinical aspects included in the recommendations previously agreed as a consensus $[1,3,13-15]$, on improving therapeutic management of this disorder, were taken into consideration. 
In primary prevention, $74 \%$ of the participants advised lifestyle modifications and, in turn, evaluated the need for pharmacological treatment with statins. In contrast, in secondary prevention with LDL-C in targets, $70 \%$ of doctors associated statins and fenofibrate from the start of treatment. The overall treatment approach to control AD reported by participants mostly matches the therapeutic algorithms published to date. Thus, most of the guidelines consider that lifestyle changes are a key strategy in the treatment of AD and the participants also considered this as being so [1, 4,1315]. These data are consistent with the results observed in the DAT-AP study, in which it was observed that phenofibrate was the most frequently selected option (90\%) for the association with statins and fibrates were considered the most effective for triglyceride decrease (57\%) and HDL-C increase (54\%), according to the available data [17,18 ].

Regarding the pharmacological approach, the guidelines recommend that the drugs of first choice should be statins, although they are not always able to reduce all cases of AD-associated risk. If the patient with AD does not achieve the treatment target with statins, a fibrate should be added, and fenofibrate is the drug of choice $[1,4,13-15]$.

Although the level of inculcation of knowledge about the therapeutic management of AD is highly acceptable in some cases, there are parts that need to be modified. It is very important to note that, surprisingly, a quarter of the participants (19\%), indicated that they fully or partially agree $(16.23 \%$ and $2.92 \%$, respectively) that Genfibrocil is suitable for association with statins and $7 \%$ of primary care physicians agreed that fibrates should not be combined with statins. These results contrast with those obtained in the 2017 DAT-AP study, in which only $10 \%$ of the physicians surveyed did so $[17,18]$. While it has been published that gembrozil is the fibrate with greatest potential for interactions and its association with statins is contraindicated. This attitude in the treatment of AD is currently inadmissible and is not endorsed by the Guidelines and Consensus of clinical practice, representing a bad practice in the therapeutic attitude of Spanish family doctors.

It should be noted that the most recent Clinical Practice Guidelines, based on available evidence, recommend that lifestyle modifications are the first step in the treatment of atherogenic dyslipidaemia. The treatment of first choice are statins, which do not eliminate all the risk, even with the patient in the goal of cLDL, remaining a residual risk attributed to the $\mathrm{AD}$, so that fibrates must be added to the statins. The fibrate of choice to associate with statins is Fenofibrate, especially in patients with high and very high CVR, being contraindicated the Genfibrocil [1, 4,13-15].

This study has some of the limitations inherent in observational design, including its susceptibility to bias and confusion, its inability to define causality. Although a cluster sampling was carried out, because one of the inclusion criteria was that doctors had experience of more than 5 years, it could induce selection bias and representativeness by Autonomous Community. Since this study is based on an electronic questionnaire, participants may misunderstand some questions and may produce information biases, so this data describes an image of the diagnostic management of AD that should be confirmed by other studies. In addition, extrapolation of the results should be done with caution, as participants may not represent all primary care physicians in Spain.

The strengths of this study are based on the fact that its results allow us to have an approximation to the reality in the management of AD by Spanish primary care physicians. They allow us to generate working hypotheses for the future. They show the heterogeneity of the doctors that contrasts with their high degree of knowledge of the Clinical Practice Guidelines that have not been transferred to their usual clinical practice. These results imply an alert and a wake-up call to improve the standard clinical practice in relation to the overall approach of AD. They allow us to approach reality and provide key information to improve the therapeutic approach of patients with AD in the Spanish healthcare system

\section{Conclusion}

The results of this study reveal that health professionals have access to general recommendations associated with AD management. As would be expected, they are aware of the risk that AD poses to the patient's health, because it is associated with a high cardiovascular risk and residual risk of lipid origin, they have high theoretical knowledge of the Clinical Practice Guidelines, although they do not put them into practice correctly. However, it is necessary to continue to increase awareness of the importance of treatment and optimal control of AD to reduce the cardiovascular risk of patients. 


\section{Compliance with ethical standards}

\section{Acknowledgments}

I am very grateful to all the participants in the study and to all the researchers involved.

\section{Disclosure of conflict of interest}

There are no conflict of interest.

\section{Statement of informed consent}

The study was approved by de Clinical Research Ethics Committee of Hospital Universitario Puerta de Hierro, Majadahonda, Madrid. All participants received information relevant to the study and gave their consent to participate in it.

\section{References}

[1] Ascaso JF, Millán J, Hernández-Mijares A, Blasco M, Brea Á, Díaz Á, Mantilla T, Pedro-Botet J, Pintó X; Grupo de trabajo sobre Dislipemia Aterogénica de la SEA. Consensus document on the management of the atherogenic dyslipidaemia of the Spanish Society of Arteriosclerosis. Clin Investig Arterioscler. Mar-Apr 2017; 29(2): 86-91.

[2] Ferrari R, Aguiar C, Alegria E, Bonadonna RC, Cosentino F, Elisaf M, et al. Current practice in identifying and treating cardiovascular risk, with a focus on residual risk associated with atherogenic dyslipidaemia. Eur Heart J. 2016; 18(Suppl.C): C2-C12.

[3] Núñez-Cortés JM, Pedro-Botet J, Brea-Hernando Á, Díaz-Rodríguez Á, González-Santos P, Hernández-Mijares, et al. Consenso de expertos sobre propuestas para la mejora del manejo de la dislipemia aterogénica. Revista Española de Cardiología. 2014; 67(1): 36-44.

[4] Ascaso JF, Pintó X, Millán J, Hernández-Mijares A, Blasco M, Brea Á, Díaz A, Pedro-Botet J, et al. Dislipemia aterogénica 2019. Documento de consenso del Grupo de Dislipemia Aterogénica de la Sociedad Española de Arteriosclerosis. Clin Investig Arterioscler. 2020; 32(3): 120-125.

[5] Boekholdt SM, Arsenault BJ, Mora S, Pedersen TR, LaRosa JC, Nestel PJ, et al. Association of LDL cholesterol, nonHDL cholesterol, and apolipoprotein B levels with risk of cardiovascular events among patients treated with statins: a meta-analysis. JAMA. 2012; 307: 1302-9.

[6] Guallar-Castillón P, Gil-Montero M, León-Muñoz L M, Graciani A, Bayán-Bravo A, Taboada J M et al. Magnitud y manejo de la hipercolesterolemia en la población adulta de España, 2008-2010: el estudio ENRICA. Revista Española de Cardiología. 2012; 65(6): 551-558.

[7] Cabrera M, Sánchez-Chaparro MA, Valdivielso P, Quevedo-Aguado L, Catalina-Romero C, Fernández-Labandera C, et al.- Prevalence of atherogenic dyslipidemia: association with risk factors and cardiovascular risk in Spanish working population. "ICARIA" study. Atherosclerosis. 2014; 235: 562-9.

[8] Ruiz-García A, Arranz-Martínez E, García-Fernández ME, Cabrera-Vélez R, García-Pliego RA, Morales-Cobos LE, et al. Related cardiometabolic factors and prevalence of low HDL-cholesterol levels and atherogenic dyslipidemia. SIMETAP-AD study. Clin Investig Arterioscler. Jan-Feb 2021; 33(1): 19-29. Spanish.

[9] Cinza Sanjurjo S, Llisterri Caro JL, Barquilla García A, Polo García J, Velilla Zancada S, Rodríguez Roca GC, et al. [Description of the sample, design and methods of the study for the identification of the Spanish population at cardiovascular and renal risk (IBERICAN)]. Semergen. 2020; 46(1): 4-15.

[10] Pedro-Botet J, Flores-Le Roux JA, Mostaza JM, Pintó X, de la Cruz JJ, Banegas JR; en nombre del grupo de investigadores EDICONDIS-ULISEA. Atherogenic dyslipidemia: prevalence and management in lipid clinics. Rev Clin Esp. 2014; 214(9): 491-8.

[11] Halcox JP, Banegas JR, Roy C, Dallongeville J, De Backer G, Guallar E, et al. Prevalence and treatment of atherogenic dyslipidemia in the primary prevention of cardiovascular disease in Europe: EURIKA, a cross-sectional observational study. BMC Cardiovasc Disord. 2017; 17(1): 160.

[12] De Backer G, Jankowski P, Kotseva K, Mirrakhimov E, Reiner Ž, Rydén L, et al. EUROASPIRE V collaborators; Writing Committee; Scientific Steering/ Executive Committee; Coordinating centre; Diabetes centre; Data 
management centre; Statistical analysis centre; Central laboratory; Study centers, organizations, investigators and other research personnel (National Coordinators in each country are indicated by asterisk. Management of dyslipidaemia in patients with coronary heart disease: Results from the ESC-EORP EUROASPIRE V survey in 27 countries. Atherosclerosis. Jun 2019; 285: 135-146.

[13] Expert Dyslipidemia Panel of the International Atherosclerosis Society Panel members. An International Atherosclerosis Society Position Paper: global recommendations for the management of dyslipidemia--full report. J Clin Lipidol. 2014; 8: 29-60.

[14] Mach F, Baigent C, Catapano AL, Koskinas KC, Casula M, Badimon L, et al. ESC Scientific Document Group. 2019 ESC/EAS Guidelines for the management of dyslipidaemias: lipid modification to reduce cardiovascular risk: The Task Force for the management of dyslipidaemias of the European Society of Cardiology (ESC) and European Atherosclerosis Society (EAS). European Heart Journal. 2019; 00: 1-78.

[15] Pedro-Botet J, Ascaso JF, Blasco M, Brea Á, Díaz Á, Hernández-Mijares A, Pintó X, Millán J; Grupo de trabajo sobre Dislipidemia Aterogénica, Sociedad Española de Arteriosclerosis. Triglycerides, HDL cholesterol and atherogenic dyslipidaemia in the 2019 European guidelines for the management of dyslipidaemias. Clin Investig Arterioscler. 2020 Sep-Oct;32(5):209218.

[16] Ministerio de Sanidad, Política Social e Igualdad. 2011. Informe sobre oferta y necesidad de especialistas médicos en España. 2010-2025.

[17] Díaz Rodríguez A, Cumplido AS, Nuñez-Cortés JM, Rodríguez de Miguel M, Orera-Peña ML. The application of atherogenic dyslipidaemia consensus recommendations in the primary care setting. DAT-AP study. Clin Investig Arterioscler. 2017; 29: 178-84.

[18] Díaz Rodríguez A, Cumplido AS, Nuñez-Cortés JM, Orera-Peña ML, Rodríguez de Miguel M. Implementation of proposals for management of atherogenic dyslipidemia in primary care. Results of the DAT-AP study. Ejpmr. 2017; 4(4): 616-622. 